\title{
Ancillary Impacts of Harvest Residue Pelletization
}

\section{Ryan Jacobson'1, Shahab Sokhansanj1, Dominik Roeser', Jason Hansen², Bhushan Gopaluni', Xiaotao Bi ${ }^{1}$}

${ }^{1}$ University of British Columbia, Vancouver, Canada

${ }^{2}$ Idaho National Lab, Idaho Falls, USA

Email: shahab.sokhansanj@ubc.ca

How to cite this paper: Jacobson, R., Sokhansanj, S., Roeser, D., Hansen, J., Gopaluni, B. and Bi, X.T. (2021) Ancillary Impacts of Harvest Residue Pelletization. Journal of Sustainable Bioenergy Systems, 11, 144-155. https://doi.org/10.4236/jsbs.2021.113011

Received: June 30, 2021

Accepted: September 20, 2021

Published: September 23, 2021

Copyright $\odot 2021$ by author(s) and Scientific Research Publishing Inc. This work is licensed under the Creative Commons Attribution International License (CC BY 4.0).

http://creativecommons.org/licenses/by/4.0/ (c) (i) Open Access

\begin{abstract}
This paper analyzes the implications on employment, taxation, and wildfire fuel reduction costs when using mobile pellet mills to remove biomass and reduce wildfire fuels. Wildfire suppression costs in British Columbia have exceeded the set budget in 9 of the last 10 years and the province has only reduced the fuel load on a fraction of the high-risk hectares. Using a novel high-moisture mobile pellet mill allows the production of 89,000 tonnes of wood pellets each year for a price of $\$ 293$ tonne $^{-1}$. Each tonne produced also provides $\$ 546$ tonn $^{-1}$ in additional benefits from employment, taxation, and reductions in the cost to perform fuel treatments. The presented research found that 11 employees are needed to operate a mobile pellet mill, with total employment of 242 for 22 systems across BC. The assessed system can also avoid $\$ 5.5$ million in employment insurance payments. The 22 systems also provide $\$ 323,000$ in taxable profits and $\$ 524,000$ from income taxes from employees. Fuel treatment with the researched systems costs $\$ 1112 \mathrm{ha}^{-1}$. A cost-benefit analysis shows that the system provides $\$ 2.97$ in benefits for every dollar invested.
\end{abstract}

\section{Keywords}

Bioenergy, Harvest Residues, Mobile Pelletization, High Moisture

\section{Introduction}

Wildfires have been responsible for destroying several communities in western Canada, the most recent being Fort McMurray, Alberta and Lytton, British Columbia [1]. In 2021 in Lytton, British Columbia, a record setting heatwave combined with high winds and uncontrolled sagebrush and forests destroyed almost 
$90 \%$ of the town in hours [2]. Events such as these have highlighted the need for more aggressive forest and rangeland management practices. $\mathrm{BC}$ has funded several efforts to protect communities and vulnerable forests and habitats from wildfire and other adverse effects where management plans can mitigate effects [3] [4]. Remote forestland is expensive to log and manage due to distance and lack of infrastructure. Wildfires are natural forest management, and when fires are suppressed without instating management activities, the timber and undergrowth develop problems. Unmanaged forests allow increased trees per hectare, resulting in a competition that weakens the trees and makes them susceptible to infection and infestation and allows undergrowth to strangle trees. As timber and undergrowth volumes naturally increase on these lands, the risk of extreme wildfires grows; these fires burn more intensely than historical fires and can kill coniferous seeds that rely on wildfires to germinate and damage, sterilize, or even glass soil. These fires spread rapidly and behave uniquely, threatening wildfire suppression crews and communities. Feedstock prices can be controlled much more carefully in a mobile pellet system, where the system can relocate whenever feedstock becomes scarce or more expensive. Employment per tonne produced is increased in the mobile system. Remote forests are more accessible using mobile pelletization due to limited feedstock transportation distances, where the material is the least dense in the production cycle. With the province currently experiencing a fibre shortage, it is critical for fibre-reliant industries to explore new sources and explore new forest management approaches to improve economics as well as forest health.

Forest management is the province's responsibility in most cases, as $94 \%$ of forests in the province are on crown land. Wildfire mitigation activities, which are activities that reduce the risk or severity of wildfire outbreaks such as fuel treatments, thinnings, brush removal, and developing firebreaks among many other activities [5]. British Columbia has developed several programs to improve community resilience and protection from wildfire threats. The province has treated 11,679 hectares out of an identified 1.72 million high-risk hectares and has cost $\$ 78$ million to date [6]. In the Williams Lake area, fire treatment costs an average $\$ 3400 \mathrm{ha}^{-1}$ and up to $\$ 10,000 \mathrm{ha}^{-1}$ in other areas of the province [7]. Peter et al. (2016) found that costs for the Wildland-Urban Interface (WUI) fuels treatments ranged from a high of almost $\$ 9000 \mathrm{ha}^{-1}$ to a low of approximately $\$ 268$ $\mathrm{ha}^{-1}$ [7]. $96 \%$ of treatments assessed in the study cost less than $\$ 5000 \mathrm{ha}^{-1}$, with a general trend of more extensive treatments costing less per hectare [7]. Wildfire suppression is the act of fighting a wildfire once it has ignited. Since 2008, wildfire suppression costs in the province have exceeded the suppression budget in all but one year. Wildfire suppression costs in British Columbia have averaged $\$ 745 \mathrm{ha}^{-1}$ during the last ten years. The most recent year with data, 2020, saw British Columbia expend \$213 million on suppression costs, while suppression costs in 2019, 2018 and 2017 were \$182 million, \$615 million, and 649 million respectively [8]. 
British Columbia has seen 19 sawmills, and six pellet mills have shut down since 2018 because of supply shortages and volatile prices for timber and feedstock [9]. The shutdown of these mills has led to the loss of thousands of direct jobs and indirect jobs. These jobs are in smaller communities with few jobs offering comparable wages or skill requirements. The scarcity of related jobs leads to emigration from the community or long-term unemployment. British Columbia EI offers $55 \%$ of an employee's wage for 50 weeks [10].

This paper performs a cost-benefit comparison of a mobile pellet system and a traditional pellet mill. The analysis assesses both systems' production costs, impacts on local employment, government spending, and taxation.

\section{Methods}

Both the traditional and mobile pellet mills are assessed for these categories using the same assumptions and conditions. Each system produces 90,000 tonnes of wood pellets annually in this analysis and employ harvesting crews to collect the feedstock. Each harvesting crew had an average of 5 people producing 4.2 green tonnes of feedstock per hour. Fuels treatment material is assumed to be harvested at the same rate and have the same bulk density, but with a higher cost derived from literature and include transportation costs when necessary. This analysis compares 22 mobile pellet mills operating at full capacity to a single traditional pellet mill, with both sides of the analysis producing a total of 90,000 tonnes of wood pellets annually. Road construction is another important aspect of timber harvesting and thinning or fuel treatment operations. These roads are generally unpaved but with compacted gravel beds with a surface layer of dirt or rock and allow trucks and other on-road vehicles access to the forest and much closer to the harvesting activities. Forest roads have highly variable costs depending on the construction, location, and surrounding geography. Chung et al. (2008) found that base road costs were roughly $\$ 30 \mathrm{~m}^{-1}$ [11].

Fuels treatments reduce the cost of wildfire suppression on treated hectares due to improved forest health, easier movement because of reduced tree density, and slower wildfire spread rates. Research has found a positive correlation between fuel reduction and decreased wildfire suppression costs [12]. Forest road construction is part of the harvesting costs for fuels treatment and each pellet mill is assumed to construct $10 \mathrm{~km}$ of roads each year, at a cost of $\$ 30 \mathrm{~m}^{-1}$. Fuels treatments reduce suppression costs by roughly $15 \%$ on average, or from $\$ 745$ to $\$ 630 \mathrm{ha}^{-1}$ [13]. An expected value formula can be used to estimate the yearly impact of fuels treatment hectares on overall wildfire suppression costs, based on the average number of hectares in the Prince George TSA that burn each year and the number of hectares in the Prince George TSA that are treated. Equations (1)-(4) show the calculations for the expected value of fuel reduction treatments, with increasing returns as more hectares are treated. British Columbia has had wildfires every year, so the odds of a wildfire in BC are considered $100 \%$. The odds of any one hectare of PG timberland burning are the average hectares of 
the PG TSA that have burned in the last three years divided by the average hectares burned in all British Columbia (Equation (1)). The chance to treat any one hectare of PG TSA timberland is the number of timberland hectares in the PG TSA divided by the number of hectares that provide feedstock to the mobile pellet mill (Equation (2)). The expected value of wildfire suppression is chance of a PG TSA timberland hectare burning multiplied by the cost of suppression per hectare (Equation (3)). Equation (4) shows the expected value of wildfire suppression costs on a treated hectare, wildfires in fuel treated hectares were found to reduce future wildfire suppression costs $15 \%$ on treated hectares [14]. Table 1 summarizes the reduction of wildfire suppression costs through fuels treatments.

$$
\text { Chance of PGTSA Hectare Burning }=\frac{\text { Avg. PG TSA hectares burned }}{\text { Avg. BC hectares burned }}
$$

$$
\text { Chance Treat PG Hectare }=\frac{\text { Hectares Mobile Pellet Mill cantreat }}{\text { PG TSA Timberland Hectares }}
$$

$$
\text { EV of wildfire suppression on PG TSA Hectare }\left(\$ \cdot \mathrm{ha}^{-1}\right)
$$

= Chance of PG hectare burning * cost of wildfire suprression per hectare

EV of Wildfire Suppression Costs After Treatment

$$
=\mathrm{EV} \text { of wildfire suppression } * \text { Impact of fuel reduction }
$$

Both the traditional and mobile pellet mills provide employment at the pellet mill and in the forest with feedstock harvesting crews. Sawmills employ 26 people on average in BC and pellet mills employ 10 [15] [16]. For both systems, labor positions are paid $\$ 20 \mathrm{hr}^{-1}$ and managers are salaried at $\$ 60,000 \mathrm{yr}^{-1}$. Fringe benefits are included in employment costs and are $35 \%$ of pay. A mobile pellet mill requires 5 labor positions to operate the pellet mill and associated machinery, while a traditional pellet mill employs 26 . This analysis assumes that all employees for both systems would be paid from the EI benefits for the maximum time allotted if they were not employed at the pellet mill. EI benefits pay a maximum of $\$ 595$ per week, or $55 \%$ of previous average pay, whichever is less.

Two types of taxes are calculated in this analysis: business taxes and personal income taxes. Business taxes are $27 \%$ between provincial (12\%) and federal (15\%) taxes, but only apply to any profits earned by the company. This analysis applies the taxes to the calculated Net Present Value (NPV) of each system to determine the amount of taxes that need to be paid over the lifetime of the pellet mill. Personal income taxes are a graduated system in British Columbia and are paid on gross earnings in the province. Table 2 shows the tax brackets and the rates that each bracket applies to earnings.

Table 1. Calculated reduction in wildfire suppression costs on harvested hectares.

\begin{tabular}{cc}
\hline Wildfire Suppression Cost Reduction & Average \pm S.D. \\
\hline Mobile Pellet Mill & $\$ 0.04 \pm \$ 0.02$ \\
Traditional Pellet Mill & $\$ 0$
\end{tabular}


Table 2. Applicable British Columbia income tax brackets.

\begin{tabular}{cc}
\hline Applicable British Columbia Personal Income Tax Brackets & Tax Rate \\
\hline Provincial Personal Income Tax $(<\$ 42,184)$ & $5.06 \%$ \\
Provincial Personal Income Tax $(\$ 42,185-\$ 84,369)$ & $7.70 \%$ \\
\hline
\end{tabular}

A Monte Carlo simulation was designed to establish the overall variation of the benefits each pellet mill system provides to the province. Monte Carlo simulations are a method to propagate the errors of each variable in the calculation to determine the variation of the benefits each pellet mill system provides to the province and to establish that the final values were statistically different results between the systems. There are three categories of benefits that are considered in this analysis: fuels treatment, employment, and taxation. The Monte Carlo simulation performs 600 trials to develop the distributions of the variables of interest that will be discussed in detail in this section. Each variable of interest has been assigned a probability distribution and the discrete values are determined using the Beta distribution. The beta distribution performs the same as the pert distribution and is a near-normal distribution with minimum and maximum constraints, all values in this analysis were determined through literature review [17]. Table 3 shows the variables that were used to create variation in the Monte Carlo Analysis.

Using the results of the Monte Carlo simulation, a cost benefit ratio is calculated for both pellet systems. Equation (5) is the calculation to compute the cost benefit ratio. Benefits are all the positive values calculated in the Monte Carlo simulation for wildfire and fuels treatments cost reductions, employment, and taxation. Costs are all the negative values calculated in the Monte Carlo simulation for wildfire and fuels treatments cost reductions, employment, and taxation. Cost Benefit Ratios larger than one show the project provides more benefits than costs and are a worthwhile investment. In Equation (5), benefits are any of the categories discussed below that yield a positive value and costs are any categories that yield a negative value after the Monte Carlo simulation.

$$
\mathrm{CBR}=\frac{\sum \text { Benefits }}{\sum \text { Costs }}
$$

\section{Results}

Table 4 quantifies the benefits that traditional pelletization of fuels treatments would provide to the province. The traditional pellet mill provides $\$ 13.88 \pm 22.84$ tonn $\mathrm{e}^{-1}$ in benefits to the province, with employment avoiding EI payments composing the largest portion of the benefits. Production costs in this analysis were $\$ 181.08 \pm 23.59$ tonne $^{-1}$. The feedstock harvesting crews employ 54 people and avoid $\$ 11.35 \pm 2.27$ tonne $^{-1}$ in EI benefits payments. The pellet mill employs 9 labor positions and a manager, offsetting $\$ 2.73 \pm 0.30$ tonne $^{-1}$ in EI benefits payments. Income taxes paid by the 64 employees are $\$ 1.29 \pm 0.21$ tonne $^{-1}$. The pellet mill produces $\$ 1.31 \pm 0.77$ tonne $^{-1}$ in business taxes as well. 
Table 3. The parameters given beta distributions in the Monte Carlo analysis.

\begin{tabular}{|c|c|c|c|c|c|}
\hline \multirow{2}{*}{ Monte Carlo parameters } & \multicolumn{5}{|c|}{ Beta distribution values } \\
\hline & Low & Avg & High & Alpha & Beta \\
\hline Single mill production volume (tonnes) & 2028.00 & 4056.00 & 6084 & 5.00 & 3.00 \\
\hline Number of mills & 11 & 22 & 30 & 6.50 & 2.68 \\
\hline Utilization rate & $32.50 \%$ & $65.00 \%$ & $98 \%$ & 5.00 & 3.00 \\
\hline Relocations & 4 & 8.00 & 12.00 & 5.00 & 3.00 \\
\hline Feedstock bulk density (tonne $\cdot \mathrm{m}^{-3}$ ) & 0.08 & 0.15 & 0.225 & 5.00 & 3.00 \\
\hline Feedstock moisture content (\%) & $15 \%$ & $35 \%$ & $60 \%$ & 4.20 & 3.22 \\
\hline Diesel price & $\$ 0.89$ & $\$ 1.19$ & $\$ 1.35$ & 8.89 & 2.35 \\
\hline Labor $(\$ / \mathrm{hr})$ & $\$ 15.00$ & $\$ 20.00$ & $\$ 30.00$ & 3.00 & 3.67 \\
\hline Mill employees & 3 & 5 & 8 & 3.67 & 3.40 \\
\hline Harvest employees & 3 & 5 & 8 & 3.67 & 3.40 \\
\hline Loan rate $(\%)$ & $3.25 \%$ & $6.50 \%$ & $10 \%$ & 5.00 & 3.00 \\
\hline$\%$ capital as loan $(\%)$ & $0.00 \%$ & $50.00 \%$ & $100 \%$ & 5.00 & 3.00 \\
\hline Loan term & 5 & 10 & 15 & 5.00 & 3.00 \\
\hline M\&R costs (\% capital) & $10 \%$ & $20 \%$ & $30 \%$ & 5.00 & 3.00 \\
\hline Final transport dist $(\mathrm{km})$ & 35.00 & 70.00 & 105 & 5.00 & 3.00 \\
\hline Storage cost $\left(\$ \cdot \mathrm{ft}^{-3}\right)$ & $\$ 0.50$ & $\$ 1.00$ & $\$ 1.50$ & 5.00 & 3.00 \\
\hline Residue average load $\left(\mathrm{m}^{3} \cdot \mathrm{ha}^{-1}\right)$ & 150 & 279 & 350 & 8.27 & 2.42 \\
\hline Fuel treatment average load $\left(\mathrm{m}^{3} \cdot \mathrm{ha}^{-1}\right)$ & 60 & 97.00 & 125 & 6.29 & 2.72 \\
\hline
\end{tabular}

Table 4. The value of benefits provided to British Columbia by the traditional pellet mill.

\begin{tabular}{|c|c|c|}
\hline \multirow{2}{*}{ Traditional pellet mill benefits } & \multicolumn{2}{|c|}{ Benefits (\$·tonne $e^{-1}$ ) } \\
\hline & Average & Standard deviation \\
\hline Wildfire suppression reduction EV & $\$-$ & $\$-$ \\
\hline Treatment reduction with roads & $\$-$ & $\$-$ \\
\hline Business taxes produced & $\$ 9.96$ & $\$ 0.49$ \\
\hline Income taxes produced (mill) & $\$ 0.24$ & $\$ 0.03$ \\
\hline Income taxes produced (harvesting) & $\$ 0.16$ & $\$ 0.02$ \\
\hline Income taxes produced (total) & $\$ 0.39$ & $\$ 0.03$ \\
\hline EI payments avoided (mill) & $\$ 2.45$ & $\$ 0.29$ \\
\hline EI payments avoided (harvesting) & $\$ 1.65$ & $\$ 0.31$ \\
\hline EI payments avoided (total) & $\$ 4.11$ & $\$ 0.54$ \\
\hline Total benefits & $\$ 135.94$ & $\$ 5.75$ \\
\hline
\end{tabular}

The employees of the harvesting crew pay $\$ 1.04 \pm 0.21$ tonne $^{-1}$ and the employees inside the pellet mill pay $\$ 0.26 \pm 0.03$ tonne $^{-1}$ in income taxes. The base scenario assumes no fuels treatment material is used as feedstock, resulting in no 
reduction in wildfire suppression costs or fuels treatment cost reductions. The total annual benefits provided by the traditional pellet mill in this analysis are $\$ 13.64 \pm 22.84$ tonne $^{-1}$. Table 4 shows the average and standard deviation of each category considered in the Cost-Benefit Ratio analysis for the traditional pellet mill.

Table 5 quantifies the benefits that mobile pelletization of fuels treatments would provide to the province. The mobile pelletization system provided $\$ 255.35$ tonne $\mathrm{e}^{-1}$ in benefits to the province. Production costs in this analysis were $\$ 406.76$ \pm 26.05 tonne $^{-1}$, as discussed in Chapter 3, and the selling price for the wood pellets is $\$ 180$ tonne $e^{-1}$. The system avoided EI payments of $\$ 69.76 \pm 8.24$ tonne $^{-1}$ in total, with the mill avoiding $\$ 33.78 \pm 4.03$ tonne $^{-1}$ and the harvesting crews avoiding $\$ 35.98 \pm 7.09$ tonne $^{-1}$. The system provides $\$ 6.98 \pm 0.65$ tonne $^{-1}$ in income taxes, with the pellet mill employees providing $\$ 3.92 \pm 0.46$ tonne ${ }^{-1}$ and the harvesting employees providing $\$ 3.06 \pm 0.46$ tonne $^{-1}$. The system also produces $\$ 12.56 \pm 3.64$ tonne $^{-1}$ in business taxes on profits. The largest benefit is the cost savings on fuels treatments by creating industrial harvesting opportunities, with $\$ 382.83 \pm 58.61$ tonne $^{-1}$ in savings. The reduction in wildfire suppression costs associated with the treated hectares is $\$ 0.04 \pm 0.02$ tonne $^{-1}$. The total annual benefit provided by the mobile pellet system is $\$ 245.55 \pm 76.71$ tonne $^{-1}$.

Using Equation (5) to develop the cost benefit ratio, the two systems are comparable. The mobile system has a Cost Benefit Ratio of $1.80 \pm 0.25$ and the traditional system has a CBR of $1.17 \pm 0.13$. The two Cost Benefits Ratios are significantly different from one another. Table 6 compares the cost benefit ratios of the traditional and mobile pellet mills.

\section{Discussion}

Direct employment in the traditional system is understood much better and does

Table 5. The value of benefits provided to British Columbia by the mobile pellet mill.

\begin{tabular}{ccc}
\hline Mobile pellet mill benefits & \multicolumn{2}{c}{ Benefits $\left(\$ \cdot\right.$ tonn $^{-1}$ ) } \\
\cline { 2 - 3 } Wildfire suppression reduction EV & Average & Standard deviation \\
Treatment reduction w/roads & $\$ 0.04$ & $\$ 0.02$ \\
Business taxes produced & $\$ 382.83$ & $\$ 58.61$ \\
Income taxes produced (mill) & $\$ 12.56$ & $\$ 3.64$ \\
Income taxes produced (harvesting) & $\$ 3.92$ & $\$ 0.46$ \\
Income taxes produced (total) & $\$ 3.06$ & $\$ 0.46$ \\
EI payments avoided (mill) & $\$ 6.98$ & $\$ 0.65$ \\
EI payments avoided (harvesting) & $\$ 33.78$ & $\$ 4.03$ \\
EI payments avoided (total) & $\$ 35.98$ & $\$ 7.09$ \\
Total benefits (after costs) & $\$ 69.76$ & $\$ 8.24$
\end{tabular}


Table 6. The cost benefit ratios of the mobile and traditional pellet mills.

\begin{tabular}{ccc}
\hline \multirow{2}{*}{ Cost Benefit Ratio } & \multicolumn{2}{c}{ Cost Benefit Ratio } \\
\cline { 2 - 3 } & Average & Standard Deviation \\
\hline Mobile Pellet Mill & 1.80 & 0.25 \\
Traditional Pellet Mill & 1.17 & 0.13 \\
\hline
\end{tabular}

not change in the Monte Carlo simulation, which causes the small standard deviations in the personal income tax and EI payments avoided variables. The mobile system is less understood and requires a wider range of employment to account for possible differences in operating conditions. The traditional system employs 64 people in total, with 10 at the mill and 54 harvesting feedstocks. Each pellet mill in the mobile system employs $6 \pm 1$ at the pellet mill and $7 \pm 1$ in the harvesting crew for 11 total employment positions at each mill. The system requires 22 mobile pellet mills to provide 90,000 tonnes of wood pellets each year, these 22 systems would employ 132 at the pellet mills and 157 for harvesting for a total employment of 286 positions. Table 7 shows the breakdown of the taxes paid from the mobile and traditional pellet mills.

When the mobile pellet system fills all 286 positions from workers that would have been using EI benefits, the benefits to the province are substantial. The pellet mill employees avoid $\$ 3.0 \pm 0.36$ million annually and the harvesting crews avoid $\$ 3.2 \pm 0.63$ million. The traditional pellet mill avoids $\$ 0.25 \pm 0.03$ million and the harvesting crews avoid $\$ 1.1 \pm 0.27$ million. The mobile pellet system requires additional harvesting employment because each pellet mill requires a dedicated harvesting crew but needs only a fraction of the maximum annual production of a fully mechanized harvesting crew. Table 8 shows the distribution of EI payment savings by pellet system and location of employment within the system.

For either the mobile or traditional pellet systems to pay business taxes, a profit must be earned during the fiscal year. Under the conditions used in this analysis, both systems struggle to produce a profit with a selling price of $\$ 180$ tonne ${ }^{-1}$, but the mobile pellet system cannot produce a profit without subsidies from the government to offset production costs and would never pay taxes. However, if the system is allowed to keep a $10 \%$ markup over breakeven cost, the province recovers a portion of the subsidy given to the pellet producer and the pellet producer can earn a profit. The traditional pellet mill requires no subsidy to produce a profit on average, however, many of the 600 Monte Carlo runs produced no business taxes due to not earning a profit on the sale of the pellets. The traditional system paid $\$ 1.15 \pm 0.69$ tonne $^{-1}$ in business taxes on the profits earned. The mobile system paid $\$ 12.64 \pm 3.53$ tonne $^{-1}$ on profits when using the $10 \%$ markup over breakeven costs.

The traditional pellet mill does not use fuels treatment materials as feedstock and therefore provides $\$ 0.00$ in benefits from fuels treatments. A single mobile 
Table 7. The avoided employment insurance payments by production system and stage.

\begin{tabular}{ccc}
\hline \multirow{2}{*}{ Avoided EI Payments } & \multicolumn{2}{c}{ Avoided Payments (\$) } \\
\cline { 2 - 3 } & Average & Standard Deviation \\
\hline Mobile Pellet Mill & $\$ 3,015,129.33$ & $\$ 366,783.31$ \\
Mobile Feedstock Harvesting & $\$ 3,236,951.90$ & $\$ 632,157.83$ \\
Tradtional Pellet Mill & $\$ 245,983.09$ & $\$ 25,978.73$ \\
Traditional Feedstock Harvesting & $\$ 1,119,713.70$ & $\$ 264,801.62$ \\
\hline
\end{tabular}

Table 8. The business tax payments of the mobile and traditional pellet mills.

\begin{tabular}{ccc}
\hline \multirow{2}{*}{ Business taxes payments } & \multicolumn{2}{c}{ Tax payments $\left(\$ \cdot\right.$ tonne $\left.^{-1}\right)$} \\
\cline { 2 - 3 } & Average & Standard deviation \\
\hline Mobile system business tax & $\$ 12.64$ & $\$ 1.17$ \\
Traditional system business tax & $\$ 3.53$ & $\$ 0.71$ \\
\hline
\end{tabular}

pellet mill provides a benefit of $\$ 0.01$ tonne $^{-1}$ in wildfire suppression costs reductions. However, when all 22 of the mobile pellet mills in the mobile system are considered then the wildfire suppression savings are $\$ 0.04 \pm 0.03$ tonne $^{-1}$. The savings are highly volatile and linked to fuels treatments densities per hectare and harvesting costs, with lower fuels treatments densities leading to lower suppression savings. Table 9 compares the wildfire suppression cost savings of a single mobile pellet mill with the mobile system.

The province currently pays an average of $\$ 3400 \mathrm{ha}^{-1}$ for fuel treatments. This high cost makes the savings from using a mobile pellet mill to perform fuel treatments very high. Ten kilometers of forest roads are needed each year to allow access to the hectares which are targeted for fuels treatments, which adds $\$ 0.66$ tonne ${ }^{-1}$ to fuels treatments harvesting costs. The traditional pellet mill does not use fuels treatment material in its feedstock, as the scenario was based on real world conditions and therefore receives no benefits from the activity. An individual mobile pellet mill can perform fuels treatments on $572 \pm 162$ ha of timberland in this system with a fuels treatment material density of $105.47 \pm 9.99$ tonnes $\cdot \mathrm{ha}^{-1}$. Table 10 shows the hectares that a single mobile pellet mill will treat and the hectares that the entire mobile pellet system will treat.

Harvesting and delivering fuels treatment material to a mobile pellet mill costs $\$ 55.32$ tonne $^{-1}$. Fuels Treatments in this system cost $\$ 586.08 \pm 118.80 \mathrm{ha}^{-1}$. When the entire system of mobile pellet mills is considered, 14,244 $\pm 1301 \mathrm{ha}^{-1}$ needs to be treated to provide adequate feedstock to the pellet mills. The mobile system provides $\$ 386.23 \pm 56.87$ tonne $^{-1}$ in benefits to the province. These benefits come from the savings the province would receive when comparing the current average cost per hectare of fuels treatments to the calculated cost in our model. Table 11 shows the comparison of current fuels treatment costs and the calculated costs in the mobile pellet mill model. 
Table 9. The calculated reduction in wildfire suppression costs.

\begin{tabular}{ccc}
\hline \multirow{2}{*}{$\begin{array}{c}\text { Wildfire suppression } \\
\text { cost reduction }\end{array}$} & \multicolumn{2}{c}{ Wildfire suppression cost reduction $\left(\$ \cdot\right.$ tonne $\left.^{-1}\right)$} \\
\cline { 2 - 3 } Mobile system complete & Average & Standard deviation \\
\hline Single mobile mill & $\$ 0.042$ & $\$ 0.026$ \\
\hline
\end{tabular}

Table 10. The number of hectares that can be harvested by the mobile pellet mill and the complete system.

\begin{tabular}{ccc}
\hline \multirow{2}{*}{ Fuels Treatment Hectares } & \multicolumn{2}{c}{ Fuels Treatment Hectares } \\
\cline { 2 - 3 } & Average & Standard Deviation \\
\hline Mobile System Complete & 572 & 162 \\
Single Mobile Mill & 14,244 & 1301 \\
\hline
\end{tabular}

Table 11. The cost to perform fuels treatement on a hectare of land currently and with the mobile pellet milll system.

\begin{tabular}{ccc}
\hline \multirow{2}{*}{ Fuels treatment costs } & \multicolumn{2}{c}{${\text { Cost }\left(\$ \cdot \mathrm{ha}^{-1}\right)}$} \\
\cline { 2 - 3 } & Average & Standard deviation \\
\hline Current fuels treatment costs & $\$ 3400$ & $\$ 0$ \\
Mobile pellet system costs & $\$ 583$ & $\$ 125$ \\
\hline
\end{tabular}

\section{Conclusions}

While both the traditional and mobile pellet systems in this analysis provide a positive return on investment for the province of British Columbia, the mobile pellet mill provides a statistically significant larger return. Compared to the traditional pellet mill and producing the same 90,000 tonnes of wood pellets, the mobile system also provides a much larger return in absolute value terms, distributes those impacts across a larger geographic region and is more likely to continue operations in the face of intense natural disturbances. The mobile pellet mill would provide the province with a Cost Benefit Ratio of $1.80 \pm 0.25$ or would receive $\$ 1.80 \pm 0.25$ for every dollar invested in the mobile pelletization system. The traditional pellet mill assessed in this work generates a Cost Benefit Ratio of $1.17 \pm 0.13$, or the province would receive $\$ 1.17 \pm 0.13$ for every dollar invested in a traditional pellet system. The mobile pellet mill produces wood pellets for a cost of $\$ 402.71$ tonne $^{-1}$ on average and would require a subsidy of $\$ 222.71$ tonne $^{-1}$ to break even with a pellet selling price of $\$ 180$ tonne $^{-1}$. The traditional pellet mill in this analysis produces wood pellets for a price of $\$ 182.24$ tonne $^{-1}$ on average and needs a subsidy of $\$ 2.24$ tonne $^{-1}$ to break even with a selling price of $\$ 180$ tonne $^{-1}$. The mobile pellet mill system would generate continuous direct employment of 256 positions in areas of the province that have limited economic activity. The business and personal income taxes that are produced by the mobile system are an additional benefit to the areas of operation.

A mobile pellet mill would support clearing 14,244 \pm 1301 hectares of har- 
vested timberland or $583 \pm 162$ hectares of fuel reduction thinnings. Finding productive methods for disposing of harvest residues can provide significant savings to timber companies and improve the air quality around harvesting sites compared to burning the residues on site. The mobile pellet mill moves 8 times each year in this analysis and takes 40 hours to set up again, with preferred locations allowing access to 70 acres of harvested timberland. Harvest residues collection costs are $\$ 55.32$ tonne ${ }^{-1}$ of wood pellets produced. Thinnings in British Columbia are very expensive on a per hectare basis than traditional timber harvesting or residues collection. The high cost makes these operations a good target for companies using the mobile pellet mill analyzed here. The government is already providing payments for the mobile system that can offer between eleven and twenty-one full-time positions depending on harvesting volumes needed. The province will save over $\$ 6.25$ million from EI payments on average. The employees provide the province with personal income tax payments of $\$ 6.98$ tonne $^{-1}$ of wood pellets produced.

\section{Conflicts of Interest}

The authors declare no conflicts of interest regarding the publication of this paper.

\section{References}

[1] MNP LLP (2017) A Review of the 2016 Horse River Wildfire. MNP LLP, Edmomton.

[2] Isai, V. (2021) Heat Wave Spread Fire that "Erased" Canadian Town. The New York Times.

[3] Allen, J. (2018) Factsheet: Sustainable Forest Management in British Columbia. Naturally: Wood, 1-4. https://www.naturallywood.com/

[4] Gilani, H.R. and Innes, J.L. (2020) The State of British Columbia's Forests: A Global Comparison. Forests, 11, Article No. 316. https://doi.org/10.3390/f11030316

[5] Minister of Forests, Lands, and Natural Resource Operations and Rural Development (2020) Crown Land Wildfire Risk Reduction Planning Guide 2020-2021. Ministry of Forests, Lands, Natural Resource Operations and Rural Development, Victoria.

[6] Association of BC Forest Professionals (2005) Forest Fires in British Columbia. Association of BC Forest Professionals, Vancouver, BC.

[7] Peter, B., Milovanovic, M., Cataldo, N. and Scott, M. (2016) On-Reserve Forest Fuel Management under the Federal Mountain Pine Beetle Program and Mountain Pine Beetle Initiative. The Forestry Chronicle, 92, 295-297. https://doi.org/10.5558/tfc2016-055

[8] The Government of British (2021) Columbia British Columbia Wildfire Service, Wildfire Averages, Wildfire Season Summary-Province of British Columbia. https://www2.gov.bc.ca/gov/content/safety/wildfire-status/about-bcws/wildfire-hist ory/wildfire-season-summary

[9] Job Bank (2019) Labour Market Bulletin-British Columbia.

[10] Government of Canada, Employment and Social Development Canada (2015) EI 
Regular Benefits: How Much Could You Receive? https://www.canada.ca/en/services/benefits/ei/ei-regular-benefit/benefit-amount.html

[11] Chung, W.C., Stückelberger, J.S., Aruga, K.A. and Cundy, T.W.C.W. (2008) Forest Road Network Design Using a Trade-Off Analysis between Skidding and Road Construction Costs. Canadian Journal of Forest Research, 38, 439-448 https://doi.org/10.1139/X07-170

[12] Keenan, R.J., Weston, C.J. and Volkova, L. (2021) Potential for Forest Thinning to Reduce Risk and Increase Resilience to Wildfire in Australian Temperate Eucalyptus Forests. Current Opinion in Environmental Science \& Health, 23, Article ID: 100280. https://doi.org/10.1016/j.coesh.2021.100280

[13] Prichard, S.J., Peterson, D.L. and Jacobson, K. (2010) Fuel Treatments Reduce the Severity of Wildfire Effects in Dry Mixed Conifer Forest, Washington, USA. Canadian Journal of Forest Research, 40, 1615-1626. https://doi.org/10.1139/X10-109

[14] Thompson, M.P., Vaillant, N.M., Haas, J.R., Gebert, K.M. and Stockmann, K.D. (2013) Quantifying the Potential Impacts of Fuel Treatments on Wildfire Suppression Costs. Journal of Forestry, 111, 49-58. https://doi.org/10.5849/jof.12-027

[15] Macaskill, G. (2019) Economic Impacts of Northern Pulp Nova Scotia. Gardner Pinfold Consultants Inc., Sackville.

[16] Rasmussen, G. (2019) Forestry Crisis Has B.C. Town Hanging by a Thread. CBC News.

[17] Sinharay, S. (2010) Continuous Probability Distributions. In: Peterson, P., Baker, E. and McGaw, B., Eds., International Encyclopedia of Education, 3rd Edition, Elsevier, Oxford, 98-102. https://doi.org/10.1016/B978-0-08-044894-7.01720-6 